\title{
100 years ago
}

A remarkable phenomenon was observed at Kattenau, near Trakehnen (Germany), and in the surrounding district, on March 22. About half an hour before sunrise an enormous number of luminous bodies rose from the horizon and passed in a horizontal direction from east to west. Some of them seemed of the size of a walnut, others resembled the sparks flying from a chimney. They moved through space like a string of beads, and shone with a remarkably brilliant light. The belt containing them appeared about 3 metres in length and $2 / 3$ metre in breadth.

At Paris a Society “contre l'abus du tabac" has been formed, which intends to combat the excessive indulgence in smoking which has of late become the fashion in almost the whole of Europe. The Society offers various prizes for treatises on the

shown a clear peak in the $\Sigma_{\pi}$ massspectrum at $1405 \mathrm{MeV} / \mathrm{c}^{2}$. Such peaks are normally attributed to resonances, and the SU(6) theory has a place for one such resonance. But $1405 \mathrm{MeV} / \mathrm{c}^{2}$ is so close to the physical $\overrightarrow{\mathrm{K} N}$ region that the presence of a resonance should have an effect on $\overline{\mathrm{K} N}$ scattering at the lowest energies. An elegant $\mathrm{K}$ matrix formalism has been developed for dealing with these processes. A. D. Martin (Durham) gave an up-date on his fit to the formalism, using dispersion relation constraints to eke out the sparse data on low energy $\mathrm{K}-\mathrm{p}$ collisions. Dalitz (Oxford) agreed with Martin that there was no apparent need to invoke a quark-model resonance to explain the 1405 bump. It could be produced by non-singular mesonbaryon (i.e. antikaon-nucleon or pionhyperon) interactions, complicated in this region by cross-couplings between the channels.

There is great interest in the $\Lambda$ (1405) question among physicists studying strange-particles in complex nuclei. Here the binding energy brings down the effective nucleon mass, and Fermi motion adds further complications. Dover (Brookhaven) gave a review of the work that has been done on hyperfragment formation by pion and kaon beams. Little has changed since last year's hyperfragment and $\mathrm{K}^{-}$ conference in Warsaw (proceedings to be published in Nucleonika) but he illustrated how the new generation of precision spectrometer experiments is extending nuclear structure studies into this intriguing field. Batty (Rutherford) reviewed kaonic $\mathrm{X}$-ray studies. On heavy nuclei no one knows how the observed level-shifts and line-broadenings should be related to low energy kaon-nucleon processes, but his collaboration (working at NIMROD) has set a puzzle by measuring a line which may be due to the $2 \mathrm{p}$ to $1 \mathrm{~s}$ transition in antikaonic-hydrogen. The line is narrow and is not shifted significantly from the position predicted for it with a

David J. Miller is in the Department of Physics and Astronomy, University College, London. human health and the dangers it is subject to from excessive use of tobacco.

The Archaeological Society of Athens has purchased about half the village which stands upon the ruins of the Temple of Eleusis. The Society intends building new dwelling-house in another part, and to begin with excavations as soon as the present inmates of the village have moved.

The astronomer, Herr Rudolf Falb, well known through his theory of earthquakes, has returned from his South American exploring tour, which extended over a period of more than two years. In his researches he was led in the direction of ethnography and linguistics, and believes that he has made interesting discoveries regarding "the original language of the human race."

from Nature 22; May 20, 64-66; 1880.

Coulomb potential alone. This suggests a very weak antikaon nucleon coupling at threshold $\left(1432 \mathrm{MeV} / \mathrm{c}^{2}\right)$, contrary to the results of all the fits, including $A$. D. Martin's. Kumar (Mc Master) claimed that he could fit the $\Lambda(1405)$ as a resonance and match the weak coupling required by the kaonic-hydrogen result, but it was not clear if his model could be made consistent with all of the available low energy KN data. If the properties of the kaonic hydrogen X-ray line are confirmed by new experiments to be done at CERN, then those of us working on low energy antikaon-nucleon collisions will have to devise totally new techniques to study the scattering cross-sections at lower energies than can be reached at the moment. We had thought that our latest results (Durham, Brussels, Warsaw, UCL collaboration) were removing the remaining anomalies and agreeing well with A. D. Martin's fit, but there are still many poorly measured channels, particularly $\mathrm{K}^{-} \mathrm{p} \rightarrow \sum^{\circ} \pi^{\circ}$ in which the $\Lambda$ (1405) should be important, and the K matrix parametrisation remains under-constrained.

\section{Oil geology in China}

\section{from A. Hallam}

As befits a country with an impressive tally of early discoveries, there is a record of 'fire in the swamp' (evidently marsh gas or methane) in the ancient Chinese Book of Changes, written in the 11 th Century $B C$. In the early 12 th century a gas well over a kilometre deep was drilled in Sichuan Province, but the beginning of the Chinese petrolem industry dates from 1907 , when a foreign crew employed by the government of the Qing Dynasty discovered Yanchang oilfield in Shanxi Province.

For most of the first half of this century oil production remained at a very modest level but since the founding of the People's Republic there has been a considerable expansion of both exploration, with the discovery of over 160 oilfields, and production, which last year reached 106 million tons, putting China among the top dozen oil producing countries in the world. The capital city of Beijing (Peking) was thus an appropriate place for an international conference on petroleum geology.*

A measure of the importance attached to the conference by the Chinese is that the participants were granted an audience in the Great Hall of the Pcople by Vice Premier Kang Shi En, who exhibited a considerable knowledge of the petroleum industry. He looked forward to a huge increase in production to help promote the so-called four modernisations (AgricuIture, Industry, Science and Technology, and National Defence).

While the conference lectures ranged far and wide the greatest interest of the overseas participants was obviously in the Chinese contributions, because Chinese oil geology has been hitherto largely a closed book to the outside world. Three matters of especial interest may be singled out. Firstly, virtually all the oil and gas has been generated in source rocks of continental origin, and the Chinese were manifestly proud at having confounded those pundits of an earlier era who had consistently argued that significant quantities of hydrocarbons could only be generated in marine deposits. Thus the giant Daquing Oilfield in the Songliao Basin of Manchuria, which accounts for half the current production of the whole country, occurs in a region which developed as a faulted depression in Jurassic times, long after the Palaeozoic seas had retreated. By the mid Cretaceous it became established as an open lake basin, persisting into the Tertiary, in which a great thickness of organically-rich clays was deposited. Wedges of fluvial and deltaic sands in the clays, combined with anticlinal structures, provide an excellent combination of reservoir, source and cap rocks with structural traps.

A seconu point of major geological interest is the occurrence under the North China Plain of so-called 'buried hill' oilfields. Huge thicknesses of shallow-water carbonates of Proterozoic to Ordovician age were subjected to extensive karstification during a lengthy period of emergence from the late Palaeozoic to the early Mesozoic, with the development of numerous small and large cavities. Subsidence under tension of a zone extending SSW from Manchuria commenced in the late Mesozoic and continued into the Tertiary. The old karst landscape was deeply buried under thick Tertiary lacustrine clays and sands. The cavities in the ancient carbonates have proved to be excellent oil reservoirs, the oil having migrated laterally from Palaeogene clay source beds, as proved by the presence in the oil of spores and pollen of that age.

A. Hallam is Lapworth Professor of Geology in the University of Birmingham. 